\title{
STRATEGI PENINGKATAN KEBERLANJUTAN DAYA SAING TEH ORGANIK
}

STRATEGY OF INCREASING THE SUSTAINABILITY OF ORGANIC TEA COMPETITIVENESS

\author{
Titah Haritul Ichwani*), Arief Daryanto*), dan Anas Miftah Fauzi ${ }^{* *}$ \\ *) Sekolah Bisnis, Institut Pertanian Bogor \\ Jl. Raya Pajajaran, Bogor 16151 \\ **) Departemen Teknologi Pangan, Fakultas Teknologi Pertanian, Institut Pertanian Bogor \\ Jl. Lingkar Akademik, Kampus Dramaga, Bogor 16680
}

\begin{abstract}
Tea industry is a promising industry, especially with its global awareness about organic tea. The purpose of this study is to identify the best alternative strategies for PT Harendong Green Farm to survive and sustainable. Technique of data collecting was conducted by interviewing the experts and distributing the questioners to five respondents, consisting of CEO, Plantation Head and Production Head of PT Harendong Green Farm, Head of Promotion Board of Indonesia, and Tea Master. The data analysis was carried out using Analytical Hierarchy Process (AHP) method to determine strategy in detail and priority development activity for the company. AHP results show that the procurement of premium tea products, competitive pricing, attractive packaging and cultural orientation through education and understanding to the community become an alternative offered. The recommended strategy is to establish a premium tea product from a competing company with a distinctive fragrance and flavor.
\end{abstract}

Keywords: competitiveness, organic certificates, organic tea, premium tea, AHP

\begin{abstract}
Abstrak: Industri teh merupakan salah satu industri yang menjanjikan, terutama dengan kesadaran masyarakat global tentang teh organik. Tujuan Penelitian ini adalah untuk mengidentifikasikan alternatif strategi yang terbaik bagi perusahaan agar dapat bertahan serta berkelanjutaan. Teknik pengumpulan data menggunakan wawancara pakar dan pengisian kuesioner oleh lima responden yaitu CEO, Kepala Perkebunan dan Kepala Produksi PT Harendong Green Farm, Kepala Promosi Dewan Teh Indonesia dan Tea Master. Analisis data menggunakan metode Analytical Hierarchy Process (AHP) untuk menentukan strategi secara detail dan prioritas utama pengembangan kegiatan perusahaan. Hasil AHP menunjukkan bahwa pengadaan produk teh premium, harga yang kompetitif, kemasan yang menarik dan orientasi budaya melalui edukasi dan pemahaman kepada masyarakat menjadi alternatif yang ditawarkan. Strategi yang disarankan adalah dengan mengadakan produk teh premium yang berbeda dari perusahaan pesaing dengan menonjolkan aroma dan rasa yang khas.
\end{abstract}

Kata kunci: daya saing, sertifikat organik, teh organik, teh premium, AHP

\footnotetext{
${ }^{1}$ Alamat Korespondensi:

Email: ichwanititahharitul@gmail.com
} 


\section{PENDAHULUAN}

Komoditas teh dalam perekonomian Indonesia dinilai cukup strategis, karena mampu menyerap sekitar 300.000 pekerja dan menghidupi sekitar 1,2 juta jiwa (Suprihatini, 2015). Pada era perdagangan bebas, produsen teh Indonesia baik yang berupa small holder, perusahaan swasta dan BUMN sedang menghadapi persaingan ketat dengan produsen dari negara lain. Perdagangan internasional menuntut semua negara produsen, termasuk Indonesia untuk dapat meningkatkan nilai dan volume ekspor produknya agar dapat berdaya saing kuat di pasar internasional (Zakariyah et al. 2014). Pertumbuhan ekspor teh Indonesia jauh di bawah pertumbuhan ekspor teh dunia bahkan mengalami pertumbuhan negatif (Suprihatini et al. 2005), seperti pada Gambar 1.

Produksi dan konsumsi teh dunia terus menunjukan peningkatan yang signifikan dalam kurun waktu lima tahun terakhir sejak 2011, seperti pada Gambar 2. Hal ini mengindikasikan adanya permintaan terhadap teh yang cukup baik di pasaran. Adanya inovasi pada posisi hulu seperti teknologi mampu meningkatkan produksi. Inovasi pada teknologi berperan dalam menciptakan inovasi proses, inovasi produk, dan adaptasi terhadap segmen pasar yang baru (Suprihatini, 2015). Pada sektor hilir, adanya inovasi terhadap pengembangan produk turunan teh seperti ready to drink, bertambahnya variasi rasa, dijadikannya teh sebagai bahan makanan dalam kemasan yang menarik, mampu meningkatkan permintaan pasar (ITPC, 2013). Pasar domistik menunjukan pertumbuhan produksi teh olahan yang meningkat rata-rata $6,78 \%$ setiap tahunnya (Wiedjarnako et al. 2015).

Harga teh curah di pasaran menunjukan trend peningkatan yang sangat baik sejak Maret 2016, setelah sebelumnya terjadi badai El Nino yang berdampak kepada penurunan hasil produksi di banyak negara produsen teh. Harga pasaran teh curah dunia saat ini $\$ 3.21 / \mathrm{kg}$ per 31 September 2017 yang dapat dilihat pada Gambar 3. Diprediksikan bahwa dengan membaiknya kondisi politik di negara-negara produsen teh, berkembangnya pengetahuan terhadap proses produksi dan pemasaran dapat meningkatkan harga teh.

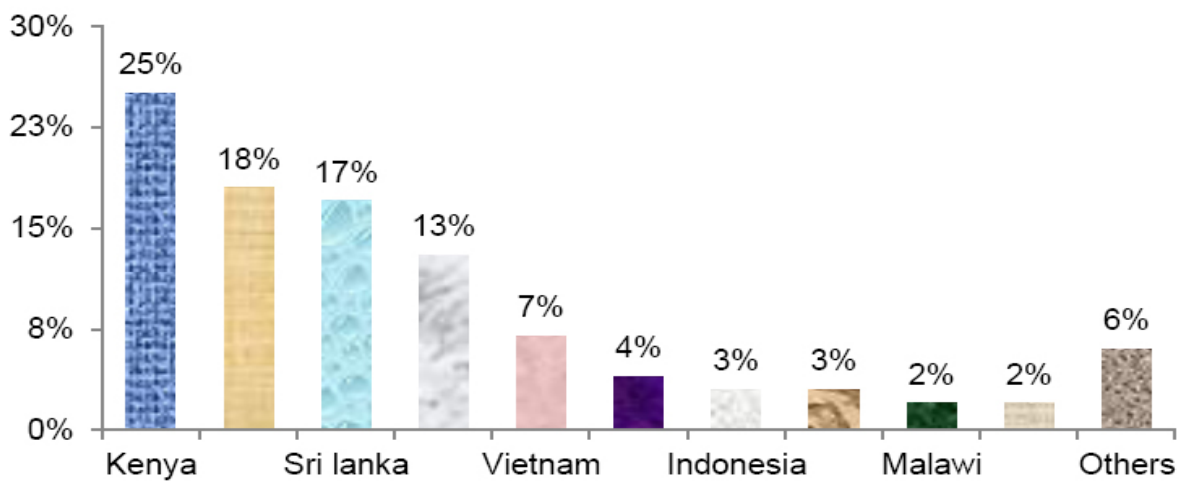

Gambar 1. Ekspor teh dunia tahun 2015 (ITC,2016)

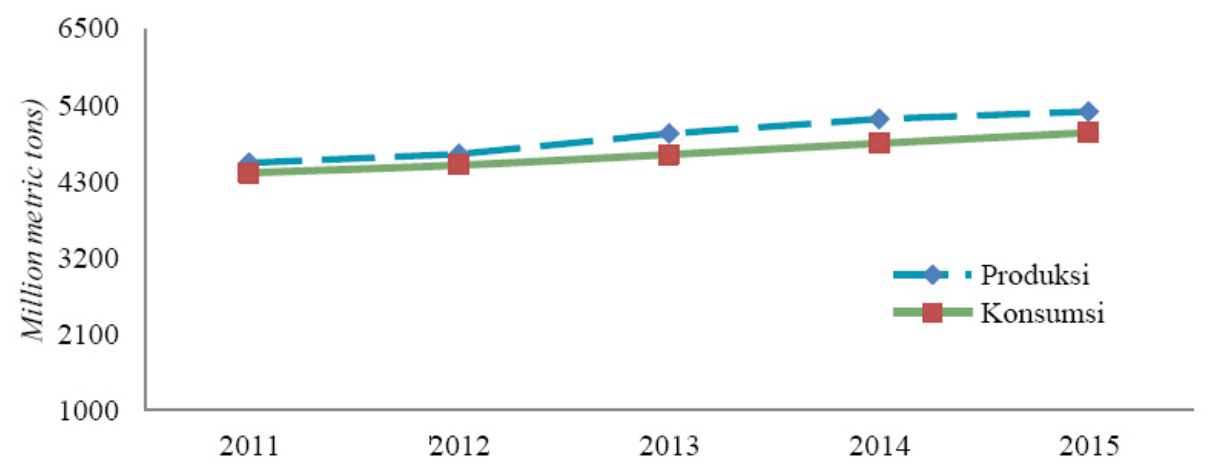

Gambar 2. Produksi dan konsumsi teh dunia tahun 2015 (ITC,2017) 
Peningkatan produksi dan konsumsi teh dunia diiringi dengan semakin membaiknya harga teh di pasaran tidak sejalan dengan perkembangan ekspor dan impor teh Indonesia yang terus menurun dalam kurun waktu lima tahun terakhir, yaitu dari jumlah 75.450 ton di tahun 2011 menjadi 67.314 ton pada tahun 2015 seperti pada Gambar 4. Pertumbuhan ekspor teh Indonesia jauh di bawah pertumbuhan ekspor teh dunia bahkan mengalami pertumbuhan negatif (Suprihatini et al. 2005). Saat ini bea masuk teh impor sebesar $0 \%$ sebagai konsekuensi Indonesia dalam kerja sama ASEAN Free Trade Agreement (AFTA) semakin memperbesar arus masuk teh impor (Darmawan et al. 2015).

Marimin dan Karmila (2004) menyatakan bahwa penurunan pangsa pasar teh Indonesia, meningkatnya jumlah teh yang tidak terjual, dan rendahnya harga teh Indonesia, dapat disebabkan oleh lemahnya kinerja perusahaan (kebun), serta ketidaksesuaian kualitas teh yang diproduksi dengan kualitas teh yang diharapkan pelanggan. Pada Gambar 5 dapat dilihat bahwa jumlah produksi teh Indonesia sejak 2015 memang menunjukkan trend positif. Namun, jumlah produksi ini belum mampu mencapai jumlah produksi tahun-tahun sebelumnya. Di samping itu, konsumsi teh Indonesia yang sebelumnya selalu berada diatas $50 \%$ dari total produksi Indonesia, menunjukkan penurunan.

Teh organik asal Indonesia juga mengalami permintaan yang baik dari pasar dunia. Tercatat transaksi teh organik sebesar US $\$ 500.000$ selama tiga hari dalam World Tea Expo (WTE) pada 6-8 Mei 2015 di California, AS. Jumlah tersebut didapat dari trial order selama pameran tersebut berlangsung. Teh organik Indonesia mendapatkan antusiasme dan respon yang positif dari para pembeli maupun pengunjung selama acara tersebut berlangsung. Teh organik jenis sinensis saat ini dihargai pada kisaran $\$ 25-\$ 100 \mathrm{~kg}$. Meskipun terdapat beragam teh premium dan organik dari negara produsen lainnya. Teh organik Indonesia saat ini memiliki momentum yang sangat strategis untuk berkembang di pasar Amerika Serikat (AS). Bahkan pada WTE yang diadakan 13-15 Juni 2017, terjadi lonjakan permintaan terhadap teh organik Indonesia. Mengingat ekspor teh Indonesia ke AS meningkat $33 \%$ dan mencapai nilai ekspor $\$ 9$ juta AS. Perusaahan dapat masuk ke pasar AS karena dapat memenuhi standar Food and Drug Administration (FDA) dan fair packaging and Labelling act (ITPC, 2013).

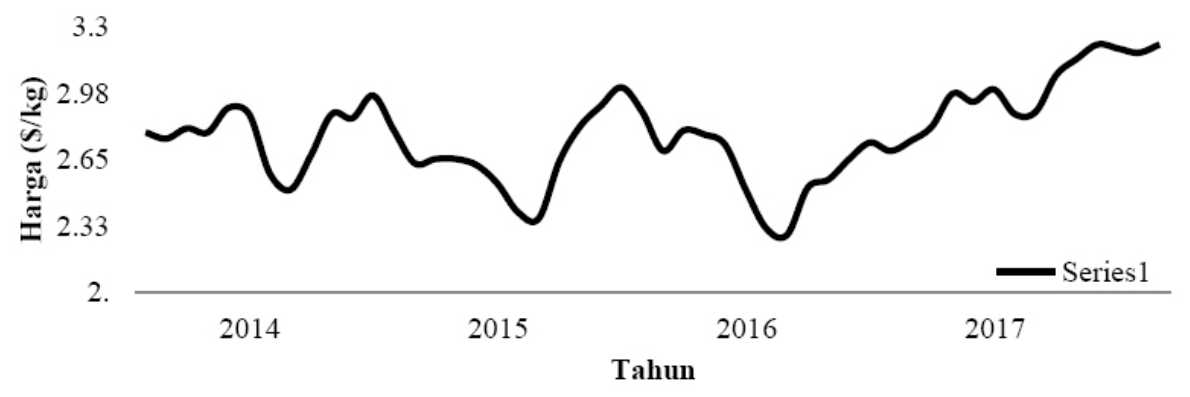

Gambar 3. Harga teh dunia (World Bank for Comodity Market, 2017)

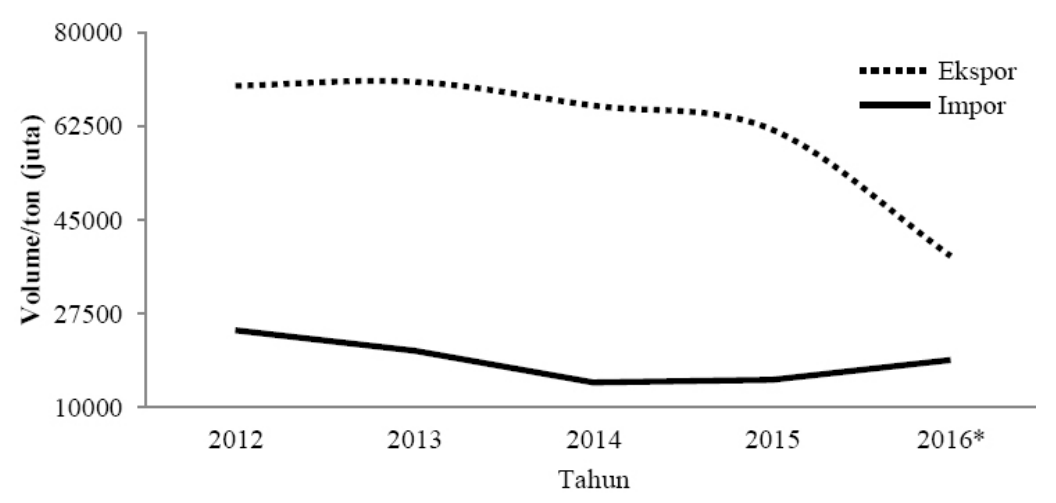

Gambar 4. Ekspor dan impor teh Indonesia 2012-2016* (DITJENBUN Pertanian, 2016) 


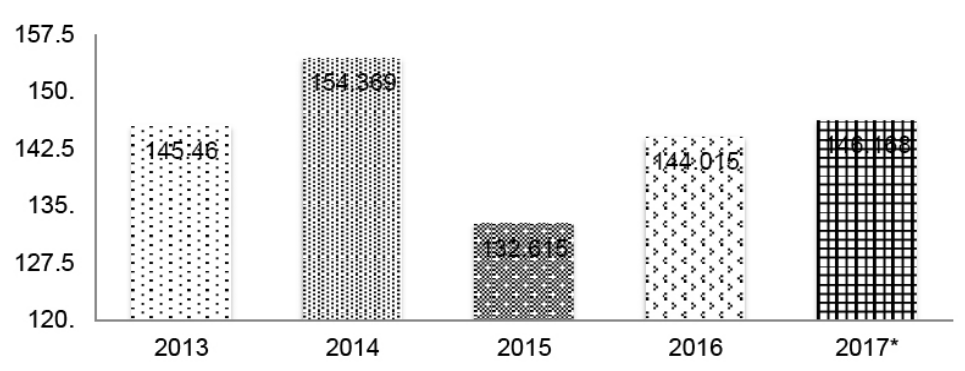

Gambar 5. Produksi Teh Indonesia 2013-2017 (DITJENBUN Pertanian, 2017)

Zundel dan Kilcher (2007) mengemukakan pasar untuk produk organik baik di tingkat nasional dan internasional mengalami prospek peningkatan yang sangat besar. Pangsa pasar kini semakin cermat, peduli dan teliti terhadap produk yang akan dikonsumsi (Seminar, 2017). Pasar internasional menginginkan adanya sistem pelacakkan dan oresisi pada pertanian yang dapat dilacak melalui sertifikasi agroindustri yang berkelanjutan (Bongiovanni dan Lowenberg, 2004; Kraisintu dan Ting, 2011). Namun, berdasarkan penelitian yang dilakukan oleh Adiyoga et al. (2007), sistem pelacakan belum diterapkan terhadap komoditaspertanian seperti komoditassayuran di Bandung, hal tersebut menjadi suatu kendala dalam binis. Oleh karena itu, penerapan keberlanjutan daya saing dianggap perlu diterapkan mengingat terjadinya pergeseran pola konsumsi masyarakat (Trenggono et al. 2018). Inovasi dalam bidang teknologi diharapkan mampu menjembatani konsep modern pengelolaan lingkungan hijau yang mempromosikan praktek ekonomi dan pembangunan keberlanjutan (Suprihatin, 2016). Salah satu perusahaan teh organik yang telah menerapkan prinsip-prinsip keberlanjutan ialah PT Harendong Green Farm. Perusahaan mengekspor sekitar 98\% teh hitam organik jenis sinensis ke Amerika Serikat. Perusahaan melihat potensi pasar yang sangat besar di AS sehingga melalui PT Harendong International, perusahaan mengekspor produk ke AS sejak diterapkannya regulasi 21CFR820 pada tahun 2004 (Vannany et al. 2014). PT Harendong Green Farm menjual produk teh mereka dengan nama yang berbeda yaitu Banten Tea untuk penjualan Indonesia dan Arum Tea untuk pasar AS. Seiring dengan peningkatan permintaan teh organik di pasaran, maka perlu dilakukan penelitian untuk menjawab alternatif strategi yang tepat untuk meningkatkan keberlanjutan daya saing terhadap perusahaan yang memperoduksi teh organik, yaitu PT Harendong Green Farm, menentukan competitive advantage teh organik, mengetahui faktorfaktor keberlanjutan teh organik serta menganalisis faktor utama kesuksesan perusahaan dalam memperoleh sertifikat organik dan mempertahankannya.

\section{METODE PENELITIAN}

Penelitian ini dilakukan pada bulan April-November 2016. Lokasi pengumpulan data, wawancara dan pengisian kuesioner dilakukan di Jakarta dan Banten. Penelitian ini menggunakan teknik depth-interview untuk mengetahui faktor dalam meningkatkan daya saing (Alwarashdeh, 2015) dan merupakan salah satu metode dalam mengumpulkan data primer yang melibatkan pihak internal dan eksternal perusahan. Data sekunder diperoleh dari Kementrian Pertanian, Badan Pusat Statistik, Dewan Komoditas Teh Indonesia, Sustainable Agriculture Network, FAO dan literatur lainnya dapat dilihat pada Tabel 1.

Responden dipilih dengan cara purposive sampling. Hal ini digunakan dengan menggunakan pertimbangan kepakaran dan pengalaman praktis responden yang memahami tentang teh. Responden merupakan para ahli yang telah lama berkecimpung dalam industri teh dan memiliki pengetahuan terkait proses penanaman, produksi, dan pemasaran. Responden berasal dari latar belakang yang berbeda, seperti dari perkebunan, pemasaran, pemerintah dan pebisnis. Responden terdiri dari lima pakar yaitu CEO, kepala perkebunan dan kepala produksi PT Harendong Green Farm, tea master dan kepala promosi Dewan Teh Indonesia.

Metode Analytical Hierarchy Process (AHP) digunakan untuk memberikan kesempatan agar setiap pihak dapat membangun gagasan-gagasan dan mendefinisikan persoalan dengan cara membuat asumsi mereka masing-masing sehingga diperoleh suatu pemecahan yang diinginkan darinya. Berdasarkan kerangka kerja AHP, penelitian ini diawali dengan pengumpulan data dan informasi yang digunakan untuk menyusun struktur hirarki. Struktur hirarki disusun sesuai dengan kebutuhan dan didasarkan kepada data dari lima responden, yaitu PT Harendong Green Farm, Dewan Komite Teh Indonesia, dan para pelaku industri teh organik yang menguasai kondisi dan permasalahan. 
Kuesioner diberikan untuk mengetahui pembobotan setiap elemen pada seluruh tingkat. Data yang diperoleh dari responden kemudian diproses dengan menggunakan program komputer Expert Choice 2000. Hasil pengolahan kemudian dianalisis dan disajikan dalam bentuk uraian, gambar, atau tabel. Proses untuk analisis data seperti yang terlihat pada Tabel 2 .

Penelitian ini diawali dengan menelaah visi, misi, dan tujuan PT Harendong Green Farm serta melakukan wawancara dengan pihak-pihak yang dianggap kompeten di bidangnya dalam hal ini adalah pihak manajemen PT Harendong Green Farm. Berdasarkan hasil tersebut didapatkan sasaran strategi, key succes factor dalam memperoleh sertifikat organik, faktorfaktor yang memengaruhi tea sustainability dan competitive advantage teh organik. Metode AHP dimaksudkan untuk mengetahui perspektif mana yang menjadi prioritas perusahaan. Selanjutnya, dilakukan penyusunan srategi yang telah ditentukan ukurannya sebagai dasar perencanaan strategi PT Harendong Green Farm kedepannya. Adapun alur pemikiran kerangka penelitian ini dapat dilihat pada Gambar 6.

\section{HASIL}

\section{Proses Produksi Teh Organik}

Proses produksi teh organik dimulai sejak pembukaan lahan. Lahan harus bebas dari zat kimia dan memiliki unsur hara yang baik untuk daat ditanami pohon teh. Proses penanaman teh, penyuburan hingga menjaga harus mengikuti standar sertifikasi organik. Pupuk yang digunakan berasal dari kotoran hewani murni tanpa campuran zat kimia apapun. Sementara itu, dalam menjaga tanaman agar terbebas dari gangguan hama maka perlu dilakukan pengusiran hama secara berkala dengan menggunakan bahan-bahan alami seperti cairan cabe, nenas, daun jarak, dan bahan substitutusi alami lainnya. Pada saat pemetikan juga dilakukan dengan cara manual karena perusahaan ingin memastikan bahwa daun teh yang diambil adalah daun teh yang memang sudah layak untuk dipetik dan hanya tiga pucuk teratas saja.

Tabel 1. Jenis dan sumber data penelitian

\begin{tabular}{ll}
\hline Jenis data & Sumber Data \\
\hline $\begin{array}{l}\text { Data Primer } \\
\text { Subyek: Kuesioner dan Depth-interview }\end{array}$ & $\begin{array}{l}\text { CEO, Kepala Perkebunan dan Kepala Produksi PT Harendong Green Farm, } \\
\text { Ketua Promosi Dewan Teh Indonesia dan Tea Master } \\
\text { Perkebunan PT Harendong Green Farm di gunung Halimun, Banten }\end{array}$ \\
$\begin{array}{l}\text { Fisik: Observasi langsung ke lapangan } \\
\text { Data sekunder }\end{array}$ & FAO IGG Sekretariat \\
$\begin{array}{l}\text { Produksi teh dunia } 2013 \\
\text { Ekspor teh dunia 2013 }\end{array}$ & FAO IGG Sekretariat \\
Konsumsi teh dunia 2013 & FAO IGG Sekretariat \\
Ekspor teh Indonesia $2010-2014$ & Indonesia Tea Statistic \\
Harga teh dunia 2016 & FAO IGG Sekretariat \\
\hline
\end{tabular}

Tabel 2. Proses analisis data

\begin{tabular}{lll}
\hline Tahapan & Kerangka analisis & Keluaran \\
\hline $\begin{array}{l}\text { Melakukan depth } \text { interview } \\
\text { kepada para expert untuk } \\
\text { mendapatkan informasi }\end{array}$ & Analisis deskriptif & $\begin{array}{l}\text { Pemahaman mendalam } \\
\text { tentang kegiatan } \\
\text { mendalam }\end{array}$ \\
$\begin{array}{l}\text { Melakukan penilaian terhadap } \\
\text { indikator keberlanjutan dan } \\
\text { menganalisa jarak tertinggi }\end{array}$ & Gap Analysis & \\
& & $\begin{array}{l}\text { Informasi tentang gap } \\
\text { tertinggi yang dapat } \\
\text { menjadi rujukan untuk }\end{array}$ \\
\hline
\end{tabular}


Pada proses pengeringan di bagian produksi perlu dipastikan bahwa daun teh tetap diproses dengan baik untuk menjaga kualitas dan terhindar dari pemakaian atau pencamuran zat kimia. Proses ini terdiri dari pengeringan dengan menggunakan bambu, dijemur, digoreng, digiling, digoreng lagi, di oven, dan pemisahan batang yang masih mengikut. Bahan baku berupa daun teh dan proses-proses tersebut dilakukan demi mengurangi kadar air pada daun teh, juga dipisahkan batang-batang kecil yang masih mengikut pada daun.

Gambar 7 menyajikan proses produksi teh di perkebunan milik PT Harendong Green Farm, Banten. Pada saat pemetikkan daun teh dilakukan secara manual. Namun, proses pengeringan semua dilakukan secara mekanik. Ekstraksi pertama dilakukan dengan menggunakan bahan dari bambu yang bertujuan untuk menjaga daun teh agar tetap utuh. Selanjutnya, untuk penggorengan menggunakan mesin, kemudian di press agar air dalam daun semakin terkuras dengan alat khusus. Selanjutnya, daun teh dikeringkan lagi dengan mesin yang berbeda dan diikuti dengan pemanggangan menggunakan bambu dan dimasukan ke mesin oven. Pada pemisahaan batang dilakukan secara manual. Dari satu batch lahan teh yang terdiri dari 27 hektar dapat diperoleh daun teh sebanyak 10-12 ton/bulan untuk teh basah. Namun setelah melalui proses pengeringan maka akan di dapat daun teh 2,5-3 ton daun teh kering.

Status peningkatan keberlanjutan daya saing perusahaan teh organik menurut Nieves dan Rio (2010), dimensi keberlanjutan daya saing perusahaan teh organik dan hubungannya tergambar melalui pendekatan segitiga, yaitu ekonomi (pertumbuhan, efisiensi, stabilitas); sosial (inclusion dan governance); dan lingkungan (resilience atau biodiversity, sumber daya alam dan polusi). Pengukuran sustainability juga digunakan sebagai patokan untuk meningkatkan keberlanjutan daya saing. Teknologi juga diperlukan pada industri teh terutama pada bagian produksi dan distribusi. Suprihartini (2015) mengatakan bahwa perbaikan manajemen dan teknologi perlu dilakukan agar dapat menurunkan biaya distribusi khususnya pada produk akhir teh. Sejalan dengan Amanda et al. (2015) yang menyatakan bahwa perlu dilakukan minimasi biaya pada proses distribusi teh. Keberlanjutan praktek pertanian organik masih rendah dilakukan dibandingkan pertanian konvensional (Widiarta et al. 2011).

Produksi teh yang dilakukan oleh PT Harendong Green Farm merupakan penerapan perkebunan organik dengan adaptasi metode pengolahan dan teknologi dari Taiwan. menggunakan pengeringan awal daun menggunakan bambu yang telah dimodifikasi dengan mesin, perusahaan berusaha tetap menjaga kualitas produknya. Saat ini perusahaan masih memiliki keterbatasan dari segi pengadaan mesin yang digunakan. Mesin yang digunakan bukan jenis mesin besar dan terbaru. Hal ini dikarenakan perusahaan masih memiliki keterbatasan produksi sehingga diperlukan tiga proses untuk mempertahankan standar organik yaitu pada masa penanaman (perkebunan), proses pengeringan daun (produksi) dan saat dipasarkan kepada konsumen (pemasaran).

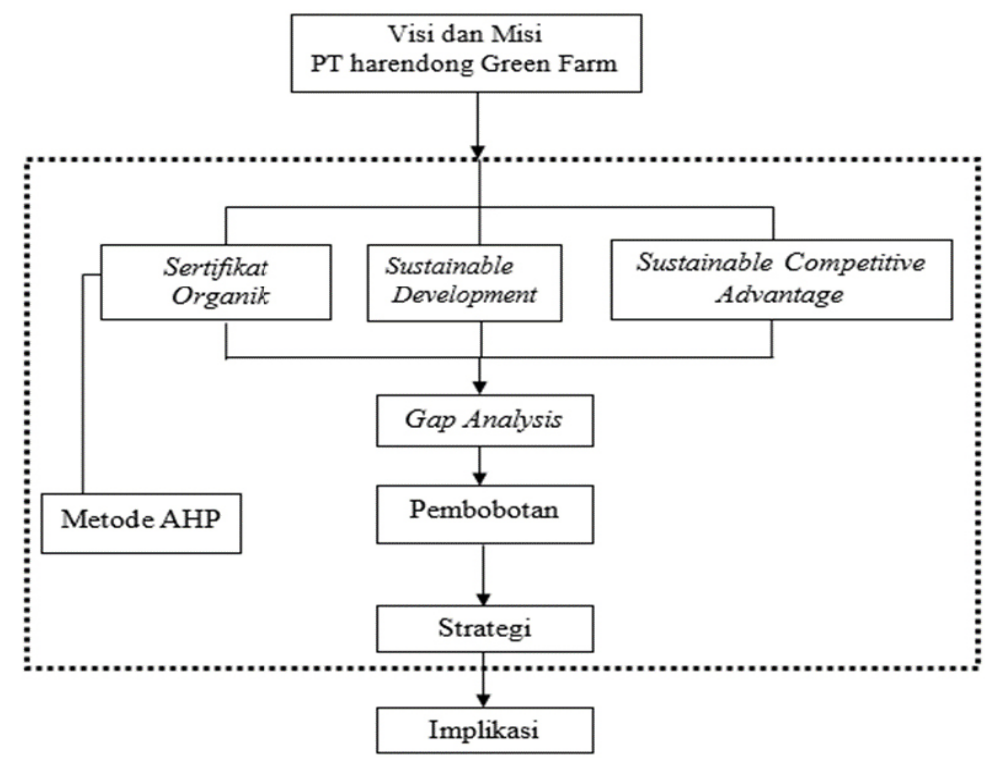

Gambar 6. Kerangka pemikiran penelitian 
PT Harendong Green Farm di Banten telah melaksanakan ketiga proses tersebut (Tabel 3). Proses penanaman dan penyuburan perkebunan menggunakan pupuk organik hasil olahan sendiri yang menggunakan standar sertifikasi organik yang diterima oleh perusahaan. Pembelian kotoran hewan dari masyarakat sekitar terbukti mampu menekan biaya pembelian pupuk organik dari pihak luar dan dapat memberikan pemasukan tambahan bagi masyarakat sekitar. Sementara pada bagian produksi, perusahaan menjaga sterilisasi lingkungan pabrik dari zat kimia untuk menghindari pencemaran daun teh yang sedang dikeringkan. Dengan proses pengeringan yang panjang dan sebagian masih dilakukan manual, perusahaan dapat melakukan pengecekkan berulang kali pada setiap tahapan untuk memastikan bahwa daun teh bebas dari campuran bahan pengawet, pewarna atau penambahan aroma. Meskipun sudah banyak aktivitas produksi teh organik sudah diterapkan, tetapi masih ada peluang meningkatkan efisiensi produksi dan perbaikan lingkungan perkebunan. Beberapa peluang penerapan produksi teh organik lebih lanjut disajikan ada Tabel 4.

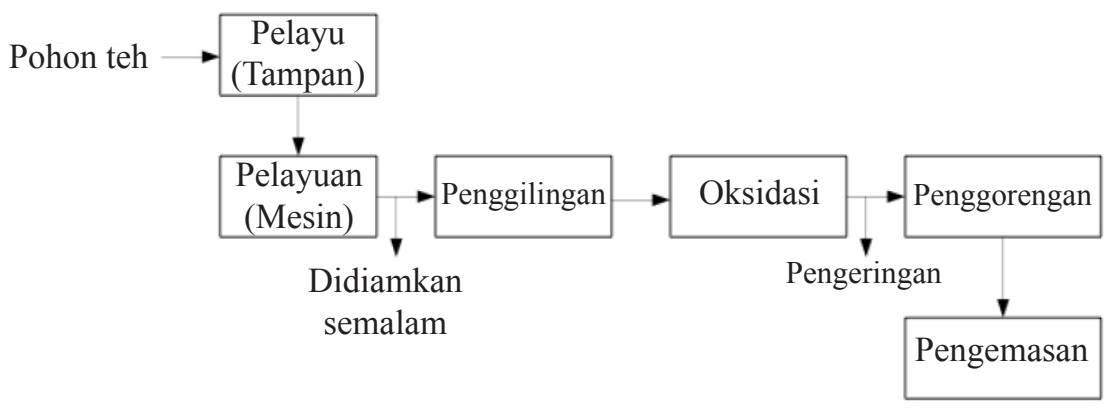

Gambar 7. Tahapan proses produksi teh

Tabel 3. Praktek perkebunan teh organik yang telah diterapkan pada perusahaan

\begin{tabular}{ll}
\hline $\begin{array}{l}\text { Indikator perkebunan } \\
\text { organik }\end{array}$ & Aspek perkebunan organik \\
\hline Perkebunan & - Menggunakan bahan alami, seperti pupuk atau kompos, untuk menyuburkan lahan dan \\
& tanaman \\
- & Menggunakan hama dan burung, gangguan pada masa kawin atau jebakan untuk mengurangi \\
& hama dan penyakit \\
- & Merotasi tanaman, tidak menggunakan bahan kimia untuk mengelola gulma \\
- & Memberi binatang makanan organik dan memberi akses keluar \\
- & Menggunakan metode pencegahan seperti merotasi pengembalaan untuk membantu \\
& meminimalisir penyakit \\
- & Tidak menambahkan pewarna agar daun teh terlihat menarik atau segar \\
- & Tidak memberikan zat yang daat meningkatkan aroma ada daun teh \\
Produksi & Tidak menggunakan zat pengawet pada saat proses pengeringan teh \\
& - Bahan pembungkus teh merupakan bahan yang dapat di daur ulang \\
- & Menggunakan kemasan tea bag dari bahan organik \\
Pemasaran & Memastikan perusahaan yang melakukan pengemasan ulang telah memiliki sertifikat organik \\
& untuk pengemasan \\
- & Mencantumkan label sertifikat organik pada kemasan \\
- & Mengharuskan para pembeli yang melakukan pengemasan ulang untuk mencantumkan asal \\
& daun teh \\
\hline
\end{tabular}


Tabel 4. Rekomendasi optimalisasi perkebunan teh organik untuk PT Harendong Green Farm

\begin{tabular}{ll}
\hline $\begin{array}{l}\text { Indikator perkebunan } \\
\text { organik }\end{array}$ & Aspek perkebunan organik \\
\hline Perkebunan & - Memiliki beberapa hewan ternak sendiri untuk menghalau hama dan menggunakan \\
& kotorannya untuk menambahkan ketersediaan pupuk \\
& - Pengoptimalan pembatasan jarak antara areal yang ditanami pohon teh dengan rumah \\
& tangga disekitar perkebunan \\
- & Pengoptimalanlahan kosong untuk menanam bahan-bahan pembuat pestisida organik. \\
& - Penambahan mesin pengeringan \\
& - Penambahan mesin diesel \\
Produksi & Menggunakan bahan kaleng sebagai tempat penyimanan teh \\
& - Mencantumkan barcode untuk dapat mengakses langsung tentang sertifikat organik \\
Pemasaran & perusahaan \\
- & Mendesain kemasan teh dengan memberikan sedikit informasi tentang oroduk organik dan \\
& kelebihannya \\
\hline
\end{tabular}

\section{Gap Analysis}

Dunn (2003) menyatakan bahwa dalam implementasi kebijakan selalu ada gap antara tujuan yang ingin dicapai dengan realisasinya. Metode gap analysis digunakan untuk menilai persepsi perusahaan teh saat ini dan harapan pencapain kinerja di masa depan. Hasil analisis menjadi acuan dalam menyusun formulasi alternatif strategi dalam mengatasi gap yang ada (Nurseppy, 2005). Terdapat tiga faktor yang diteliti yang ditentukan berdasarkan studi literatur pada beberapa penelitian yaitu sertifikat organik (Wal, 2008). sustainable development (Brundtlan, 1987) dan sustainable competitive advantage (Porter, 1990; Assauri, 2013). Setiap faktor kemudian dijabarkan melalui beberapa indikator. Analisis jarak dilakukan melalui pengisian kuisioner oleh para pakar yang terdiri CEO, Kepala Perkebunan, Kepala Produksi, Tea Master dan Ketua Promosi Dewan Teh Indonesia. Para responden memberikan penilaian dengan skala likert 1-5 pada setiap variabel yang diamati. Skala likert merupakan skala penilaian secara numerik yang menyatakan sikap setuju atau tidak setuju terhadap objek yang diamati.

\section{Analisis Peningkatan Keberlanjutan Daya Saing Perusahaan Teh Organik}

Model pengembangan daya saing dengan AHP pada perusahaan ini mengacu pada beberapa penelitian sebelumnya yang dilakukan oleh Putrianti (2014) terkait keunggulan berdaya saing teh ready to drink dan daya saing teh putih (Hage et al. 2015). AHP juga digunakan pada penelitian agribisnis teh hijau (Darmawan et al. 2015), strategi distribusi produk teh siap saji (Wiedjarnako et al. 2015), penelitian keberlanjutan udang (Fauzi et al. 2012), dan kajian strategi peningkatan kualitas teh hitam ortohodoks di PTPN VIII Persero (Marimin dan Karmila, 2004). Menurut Saaty (1993), beberapa prinsip dalam menyelesaikan AHP diantaranya identifiksi sistem, penyusunan struktur, membuat matriks perbandingan komperasi berpasangan, melakukan tahap perbandingan dan penilaian. Daya saing juga dipengaruhi oleh kualitas baik dan inovasi, standar mutu, dan pengambilan keputusan dengan tujuan yang jelas (Sidarta et al. 2016). Saat ini perusahaan secara terus menerus mencoba melakukan ekspansi agar tetap eksis (Eriyatno dan Nadjikh, 2012). Daya saing teh Indonesia cenderung sebagai negara eksportir teh (Zakaria et al. 2014). Padahal dengan pertumbuhan masyarakat kelas menengah hingga 2020 mendorong peluang teh premium untuk terbuka lebar (Hage et al. 2015). Assauri (2013) menyatakan dengan adanya keunggulan daya saing maka perusahaan akan memiliki nilai lebih dibandingkan para pesaing sejenis.

Nayantakaningtyas dan Daryanto (2012) menyatakan perlu dilakukan evaluasi strategi setiap tahunnya agar perusahaan dapat menilai kinerja perusaahan dan menentukan perbaikan kedepannya. Model strategi peningkatan daya saing PT Harendong Green Farm dan alternatif strategi kemudian divalidasi oleh para narasumber pakar dengan memperhatikan setiap aspek pada sertifikat organik, sustainable development dan sustainable competitive advantage. Alternatifpemilihan strategi dinilai tingkat kepentingannya dengan skala 1-9. Berdasarkan penilaian pakar diperoleh empat alternatif, yaitu premium tea, harga, kemasan, dan orientasi budaya. Pemilihan alternatif di dasarkan pertimbangan kriteria sertifikat organik, sustainable development, dan sustainable competitive advantage, 
sedangkan aktor terdiri dari CEO, Kepala Perkebunan, Kepala Produksi, Tea Master, dan Kepala Promosi Dewan Teh Indonesia.

Gambar 8 menunjukkan struktur AHP yang selanjutnya digunakan untuk menentukan pembobotan pada setiap kriteria, sehingga diketahui kriteria mana yang sebaiknya diutamakan oleh perusahaan pada saat penentuan strategi yang akan dilakukan. Pengembangan perusahaan teh organik membutuhkan nilai tambah sustainable competitive advantage dengan nilai pembobotan 0,389 , sustainable development $(0,341)$, dan sertifikat organik $(0,270)$. Hal ini sejalan dengan usaha peningkatan keberlangsungan daya saing perusahaan melalui sustainable competitive advantage. CEO sangat memerlukan sustainable competitive advantage dengan nilai pembobotan 0.440 . Peringkat berikutnya berturut-turut Kepala Perkebunan $(0,262)$, Kepala Produksi $(0,169)$, tea master $(0,059)$ dan Kepala Promosi Dewan Teh Indonesia $(0,063)$. Demikian pula untuk faktor sustainable development dan sertifikat organik, CEO lebih membutuhkan keduanya jika dibandingkan dengan Kepala Perkebunan, Kepala Produksi, tea master dan Kepala Promosi Dewan Teh Indonesia.
Berdasarkan analisis yang dilakukan, pada kriteria faktor diperoleh hasil bahwa sustainable competitive advantage memiliki bobot tertinggi. Sementara itu, pada aktor, CEO meraih bobot tertinggi sebagai pengambil keputusan dalam menetapkan strategi perubahan kedepannya. Diikuti dengan tujuan, bobot tertinggi berada pada kualitas. Memproduksi teh yang berkualitas menjadi hal yang perlu diutamakan perusahaan saat ini dan alternatif strategi yang meraih bobot tertinggi adalah premium tea. Hal ini sejalan dengan peningkatan kualitas teh yang diproduksi dari segi rasa, aroma, dan kualitas daun teh.

\section{Alternatif Strategi}

Gambar 9 menunjukkan hasil analisisuntukmenentukan alternatif strategi yang diperlukan oleh PT Harendong Green Farm berdasarkan perhitungan bobotnya yaitu menciptakan produk premium tea $(0,408)$. Urutan alternatif berikutnya yaitu harga $(0,291)$, kemasan $(0,177)$ dan orientasi budaya $(0,125)$. Produk premium tea harus dapat direalisasikan karena produk ini dapat menjadi produk unggulan sekaligus pembeda dengan produk perusahaan yang memproduksi teh lainnya baik organik ataupun non organik. Mengingat premium tea dapat menjadi citra perusahaan untuk lebih mudah dikenal oleh konsumen.

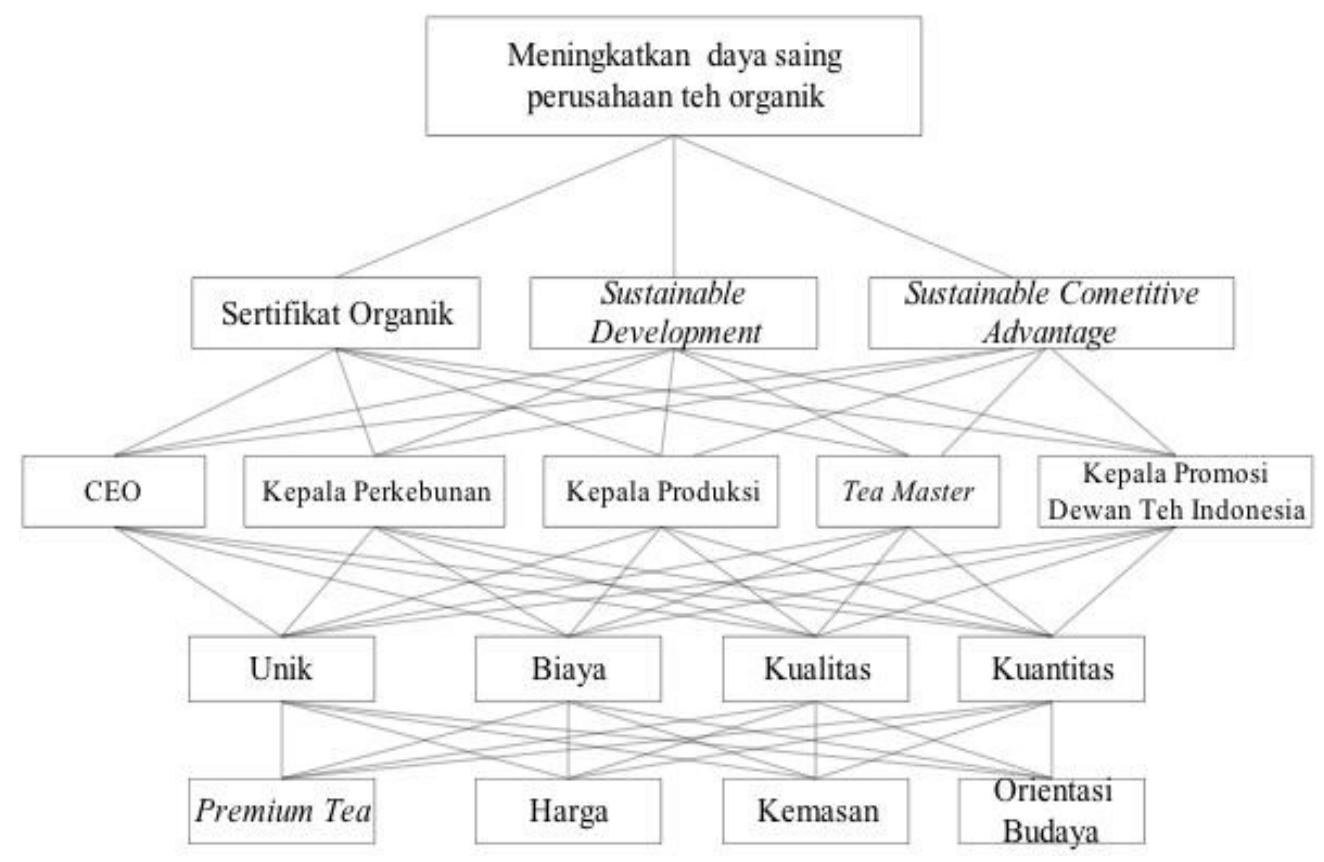

Gambar 8. Struktur AHP pemilihan alternatif strategi untuk PT Harendong Green Farm 


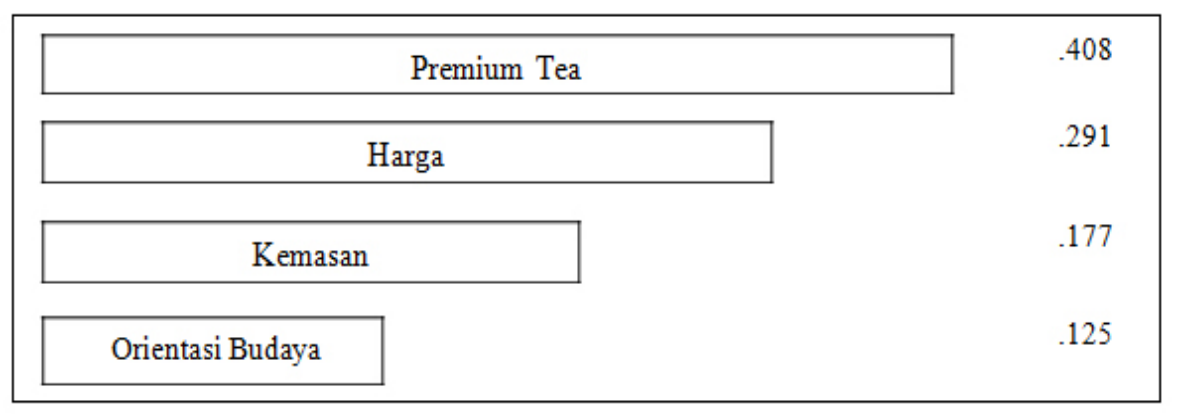

Gambar 8. Struktur AHP pemilihan alternatif strategi untuk PT Harendong Green Farm

\begin{abstract}
Alternatif strategi peningkatan keberlanjutan daya saing perusahaan teh organik berupaya memadukan strategi keberlanjutan berdaya saing untuk mengembangkan pasar yang lebih luas pada pasar domestik maupun internasional. Dengan demikian, diperlukan pengetahuan mengenai situasi internal yang dimiliki dan kondisi eksternal yang dihadapi oleh perusahaan saat ini. Strategi bagi peningkatan daya saing PT Harendong Green Farm sebagi berikut: Menciptakan produk premium tea dengan merek perusahaan sendiri. Pemakaian king leaf dari musim panen terbaik yang mengeluarkan aroma dan rasa yang khas sehingga memiliki cita rasa yang berbeda dari pesaing; Melakukan inovasi tampilan kemasan yang fungsional dan menarik dengan menyertakan metode pembuatan teh, khasiat dan sejarahnya; Menawarkan harga yang kompetitif, baik melalui produk premium dengan harga yang terjangkau oleh konsumen pada negara tujuan, maupun pada produk di level medium dengan harga yang relevan; Perusahaan dapat melakukan edukasi terkait keberlanjutan dan proses menyeduh teh yang benar dengan mengkaitkan latar belakang budaya.
\end{abstract}

\section{Implikasi Manajerial}

Peningkatan keberlanjutan yang dapat berdaya saing bagi perusahaan teh organik diharapkan dapat menjadi nilai tambah dalam proses pemasaran produk, image perusahaan, menentukan brand position di industri teh, dan dapat mengedukasi konsumen tentang teh organik. Hasil penelitian, terdapat beberapa hal yang perlu dilakukan oleh PT Harendong Green Farm untuk meningkatkan keberlangsungan daya saing perusahaan. Hasil analisis memperlihatkan bahwa perusahaan perlu menyiapkan langkah-langkah strategis sebagai berikut:
Pasar Domestik dan Internasional menunjukkan permintaan positif dengan semakin banyakanya permintaan, strategi yang dapat dilakukan perusahaan antara lain: Memaksimalkan dukungan dari pemerintah, Dewan Teh Indonesia, Asosiasi Teh, dan pihak terkait terutama dalam mempromosikan kelebihan teh organik yang memiliki khasiat jauh lebih sehat; Pengembangan wilayah pemasaran ke pasar non tradisional seperti ke wilayah Timur Tengah seperti Turki dan Arab Saudi, serta beberapa negara Eropa seperti Spanyol dan Italia; Meningkatkan peran ITPC (Indonesian Trade Promotion Centre) sebagai marketing dan market intelligence agent untuk melakukan penetrasi pasar dan meningkatkan kinerja ekspor ke negara ITPC berada dan meningkatkan kemamuan dalam mengidentifikasi peluang pasar, informasi kebutuhan produk, hambatan perdagangan, jaringan distribusi dan logistik; Sosialisasi dan upaya peningkatan pemahaman produk teh organik dengan bekerjasama dengan Dewan Teh Indonesia, Asosiasi The, dan media massa.

Peningkatan inovasi, dapat ditingkatkan dengan cara antara lain: Penciptaan rasa dan aroma teh yang unik, produk single origin dengan dipengaruhi oleh lahan perkebunan dan cuaca setempat; Membuat produk baru seperti melakukan pencampuran daun teh dengan daun/bunga/rempah-rempah dan beberapa tanaman lainnya sehingga memiliki rasa, aroma, dan khasiat yang baru; Membuat teh organik ready to drink dan teh instan dengan menggunakan tea bag khusus namun tetap memenuhi standar sertifikasi organik; Menambah atau mengganti mesin produksi dengan yang lebih canggih; Membuat tampilan kemasan yang fungsional dan menarik dengan menyertakan metode pembuatan teh, khasiat, dan sejarahnya; Menciptakan premium tea dengan merek perusahaan sendiri, pemakain king leaf dari musim panen terbaik yang mengeluarkan aroma dan rasa yang khas sehingga memiliki cita rasa yang berbeda dari pesaing. 


\section{KESIMPULAN DAN SARAN}

\section{Kesimpulan}

Alternatif strategi yang dapat diterapkan oleh perusahaan PT Harendong Green Farm adalah melalui Premium Tea. Memiliki sertifikasi organik yang diperoleh melalui badan IMO menjadi kelebihan tersendiri yang dimiliki oleh perusahaan untuk unggul dalam industri teh nasional yang belum banyak memiliki teh organik bersertifikat organik. Penerapan prinsip keberlanjutan juga diterapkan oleh perusahaan dengan mengedepankan perhatian terhadap karyawan, baik yang berada di kantor pemasaran maupun di perkebunan. Keberlanjutan daya saing diperoleh melalui inovasi yang dilakukan secara terus menerus dan mengikuti permintaan pasar.

\section{Saran}

Perlu mencari bahan baku lainnya sebagai antisipasi kelangkaan dan melonjaknya harga bahan baku pembuatan pestisida organik. Perusahaan diharapkan lebih menitik beratkan pada mengedukasi pasar terkait sertifikat organik, dan pemahaman tentang premium tea. Selain itu, perlu dilakukan penelitian lanjutan mengenai strategi peningkatan keberlanjutan produk teh organik di PT Harendong Green Farm kedepannya untuk kemajuan perusahaan khususnya dan keberhasilan industri teh Indonesia pada umunya. Untuk penelitian dengan metode serupa, identifikasi terhadap sub determinant peningkatan keberlanjutan dapat dibuat lebih terperinci dan pengisian kuesioner dapat dilakukan oleh lebih banyak responden pakar agar mendapatkan hasil penelitian yang lebih baik. Di samping itu, dalam proses pengisian kuesioner, responden cenderung memberikan nilai yang sangat besar pengaruhnya pada setiap sub determinant, sehingga perlu ditekankan pentingnya memberikan bobot yang sesuai karena tujuannya adalah memberikan prioritas

\section{DAFTAR PUSTAKA}

Adiyoga W, Asandhi AA, Laksanawati A, Nuhartuti, Sulastrini I. 2007. Rantai pasokan sayuran dan persepsi partisipan rantai terhadap pentingnya keamanan pangan. Jurnal Hortikultura 3(17): $1-16$.
Amanda MA, Imran A, Prassetiyo H. 2015. Penentuan rute distribusi untuk minimasi biaya distribusi teh Walini ready to drink di PT Perkebunan Nusantara VIII (Persero). Jurnal Online Institut Teknologi Nasional 3(1): 260-271.

Alwarashdeh R. 2015. The competitiveness of Jordan Phosphate Mines Company (JPMC) using porter five forces. International Journal of economics and Finance 5(1):191-200. https:// doi.org/10.5539/ijef.v5n1p191.

Assauri S. 2013. Strategic Management: Sustainable Competitive Advantage. Edisi ke-2. Jakarta: Rajawali Pers.

Bongiovanni R, Lowenberg DJ.2 004 .P r e c is i o $\mathrm{n}$ Agriculture and Sustainability. Precision Agriculture 5(4): 359-387. https://doi. org/10.1023/B:PRAG.0000040806.39604.aa.

Brundtland GH. 1987. Report of the World Commission on Environment and Development: Our Common Future. Oslo: United Nations.

Darmawan H, Daryanto A, Sukardi. 2015. Strategi pengembangan PT XYZ dalam agribisnis teh hijau. Jurnal Manajemen 19(1):85-100. https:// doi.org/10.24912/jm.v19i1.107.

[DITJENBUN] Direktorat Jenderal Perkebunan. 2016. Statistik Perkebunan Teh Indonesia. Jakarta: DITJENBUN.

Dunn W. 2003. Pengantar Analisis Kebijakan Publik. Wibawa S, Asitadani D, Hadna AG, Purwanto EA, penerjemah. Jakarta: Gadjahmada University Press. Terjemahan dari: Public Policy Analysis.

Eriyatno, Nadjikh M. 2012. Solusi Bisnis untuk Kemiskinan: Model dan Formula Bisnis Konkret dan Sustainable. Jakarta: PT. Alex media komputindo.

Fauzi AM, Indrawan RD, Dewi FR, Kartika L, Slamet AS, Firmansjah S. 2012. Strategies for developing sustainable and competitive cluster for shrimp industry. Jurnal Manajemen dan Agribisnis 9(edisi khusus): 89-99.

Hage AG, Daryanto A, Sahara. 2015. Formulasi strategi untuk meningkatkan daya saing teh putih (studi kasus di Pusat Penelitian Teh dan Kina). Jurnal Penelitian Teh dan Kina 18(2): 119-130.

[ITC] International Trade Statistic Yearbook. 2017. Department of Economic an Social Affairs; Statistics Division 2016. Vol 1. New York: ITC.

[ITPC] Indonesian Trade Promotion Centre Chicago. 2013. Market Brief Teh. Amerika Serikat: ITPC.

Kraisintu K, Ting ZT. 2011. The role of tracebility 
in sustainable supply chain management [tesis]. Gothenburg: Chalmer University of Technology.

Marimin, Karmila E. 2004. Kajian strategi peningkatan kualitas teh hitam orthodoks di PT Perkebunan Nusantara VIII (PTPN VIII Persero) unit Kebun Gede, Kabupaten Cianjur. Jurnal Teknik Industri Pertanian 14(1):6-16.

Nayantakaningtyas JS, Daryanto HK. 2012. Daya saing dan strategies pengembangan minyak sawit di Indonesia. Jurnal Manajemen dan Agribisnis 9(3): 194-201.

Nieves LJ, Rio PD. 2010. Contribution of renewable energy sources to the sustainable developmeng of islands: An overview of literature and a research agenda. Journal of Sustainabality 2: 786-811. https://doi.org/10.3390/su2030783.

Nurseppy I. 2005. Analisis strategi implementasi kebijakan peningkatan daya saing industri pengolahan kelapa sawit di Provinsi Sumatera Utara melalui pendekatan kluster [tesis]. Bogor: Intitut Pertanian Bogor.

Putrianti O. 2014. Strategi keunggulan bersaing teh Walini ready to drink [tesis]. Bogor: Institut Pertanian Bogor.

Porter ME. 1990. The Competitive Advantage of Nations. Seattle: Harvard Business Review. https://doi.org/10.1007/978-1-349-11336-1.

Saaty TL. 1993. Pedoman Pengambilan Keputusan Bagi Para Manajer. Jakarta: Pustaka Binaman Pressindo.

Seminar KB. 2017. Sistem pertanian presisi dan sistem pelacakan rantai produksi untuk mewujudkan agroindustriberkelanjutan. Energidan Teknologi untuk Pertanian Industrial Berkelanjutan. Bogor: IPB Press.

Sidarta KL, Oktaviani R, Kirbrandoko. 2016. Strategi Peningkatan daya Saing PT ABCD Tbk di Industri Makanan Olahan pada Tahun 2015. Jurnal Aplikasi Bisnis dan Manajemen 2(1):7382.
Suprihatin. 2016. Teknologi hijau dalam perspektif pembangunan industri berkelanjutan. Energi dan Teknologi untuk Pertanian Industrial Berkelanjutan. Bogor: IPB Press.

Suprihatin R, Sa'id EG, Marimin, Mangunwidjaja D. 2005. Analisis kondisi komponen-komponen teknologi pengolahan di industri teh curah Indonesia. Jurnal Teknik Industri Pertanian 14(3):101-106.

Suprihatini R. 2015. Analisis supply chain teh Indonesia. Jurnal Penelitian Teh dan Kina 18(2):107-118.

Trenggono B, Daryanto A, Sanim B. 2018. Model bisnis dan strategi pengembangan usaha pada the coffee bean dan tea leaf (TCBTC). Jurnal aplikasi bisnis dan manajemen (JABM) 4(3): 398-408. https://doi.org/10.17358/jabm.4.3.398.

Vanany I,Andri KB, Puspita NF, Mardiyanti R, Winarsih WH. 2014. Rancang bangun dan implementasi electronic tracebility system untuk perbaikan rantai pasok komoditasekspor pertanian. http:// www.litbang.pertanian.go.id/ks/one/842/file/ RANCANG-BANGUN-DAN-IMPLEMEN. pdf] [ April 2017].

Wal SVD. 2008. Sustainable Issues in The Tea Sector: A Comparative Analysis of Six Leading Producing Countries. Amsterdam: SOMO.

Widiarta A, Adiwibowo S, Widodo. 2011. Analisis keberlanjutan praktik pertanian organik di kalangan petani. Jurnal Transdisiplin Sosiologi, Komunikasi, dan Ekologi Manusia 71-89. https:// doi.org/10.22500/sodality.v5i1.5831.

Wiedjarnako S, Fauzi AM, Rusli MS. 2015. Strategi distribusi produk teh siap saji. Jurnal Manajemen dan Agribisnis 12(1): 68-77. https://doi. org/10.17358/JMA.12.1.68.

Zakariyah MY, Anindita R, Baladina N. 2014. Analisis daya saing teh Indonesia di pasar internasional. Jurnal Pertanian Berbasis Keseimbangan Ekosistem 29-37.

Zundel C, Kilcher L. 2007. International Conference on Organic Agriculture and Food Security; Roma, 3-5 Mei 2007. Rome: FAO. 